\section{Commentary: Extracellular matrix tube graft in the mitral position: It's feasible, but is it durable?}

\author{
Oliver J. Liakopoulos, MD
}

In the search for the perfect heart valve substitute, decellularized extracellular matrix (ECM) from porcine small intestinal submucosa (CorMatrix, Atlanta, Ga) appears to be a potential candidate that might overcome the limitations of current mechanical and bioprosthetic valves. Introduced initially as a biological tissue substitute for pericardial or intracardiac defect closure in congenital and adult heart surgery, the flexible and robust properties of ECM, taken together with its potential for growth and regeneration, have expanded the range of its applicability into the heart valve sector, as also discussed in a recent review and shown by the numerous publications of animal and clinical studies on this topic. ${ }^{1-4}$ Nonetheless, there is an ongoing debate among experts on whether this readily available biomaterial is suitable as a heart valve substitute in terms of long-term durability and lack of immunogenic and thrombogenic properties. ${ }^{1,5,6}$

Despite promising results from animal and small clinical case series using ECM for valvular disease, recent clinical data have raised significant uncertainties with respect to the clinical efficacy, durability, and immunogenicity of this biomaterial. ${ }^{1}$ In a recent prospective, multicenter study of 103 pediatric and adult patients who underwent a total of 38 valve repairs, 6 reoperations were required due to ECM scaffold failure, and chronic inflammation was observed in the explanted tissue. ${ }^{7}$ Indeed, chronic inflammation was also observed in 8 of 9 ECM failed valve explants in another study, and altered remodeling and intense inflammation was also observed in ECM tissue explant after 10 and 18 months of left-sided valvular repair in adult patients with active endocarditis. ${ }^{8,9}$ Consistent with these findings, Kelley and colleagues $^{10}$ reported a $32 \%$ recurrence rate of severe mitral regurgitation (MR) within the first 200 days of mitral valve surgery in 44 adult patients with type III MR that was

\footnotetext{
From the Department of Cardiothoracic Surgery, Heart Center, University of Cologne, Cologne, Germany.

Disclosures: Author has nothing to disclose with regard to commercial support.

Received for publication Aug 27, 2019; accepted for publication Aug 27, 2019; available ahead of print Sept 20, 2019.

Address for reprints: Oliver J. Liakopoulos, MD, Department of Cardiothoracic Surgery, Heart Center of the University of Cologne, Kerpener Strasse 62, 50924 Cologne, Germany (E-mail: oliver.liakopoulos@uk-koeln.de).

J Thorac Cardiovasc Surg 2020;160:113-4

0022-5223/\$36.00

Copyright (c) 2019 by The American Association for Thoracic Surgery

https://doi.org/10.1016/j.jtcvs.2019.08.096
}

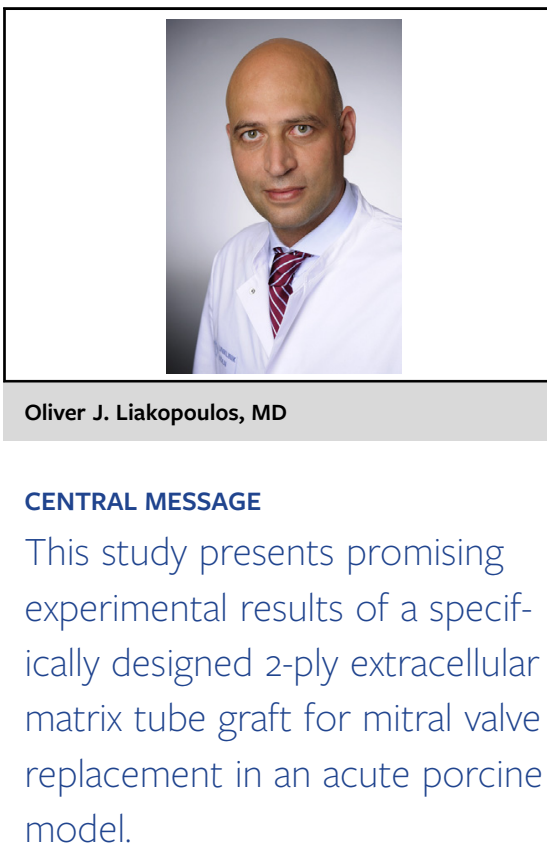

directly related to ECM patch failure. Twenty-eight percent of these patients had to undergo redo surgery in this series, a number that is simply unacceptable for many surgeons and discourages the routine use of this biomaterial.

In this issue of the Journal, Tjørnild and colleagues ${ }^{11}$ present their "preliminary" results of the concept of mitral valve replacement with a specifically designed 2-ply ECM tube graft (CorMatrix SiS material). In this acute porcine study, hemodynamic valve performance, ventricular dimensions, and geometry were serially assessed and compared with the native mitral valve apparatus. The authors describe in their advanced implantation technique a downsizing of the mitral valve circumference with the tube graft, which led to slightly elevated pressure gradients. Design or implantation-related obstruction of the left ventricular outflow tract or increased signs of systolic anterior motion were not observed, and the valve was fully functional without relevant MR after implantation.

The authors can be congratulated for their meticulous work and proof of concept of the ECM tube graft in this acute setting. Nonetheless, all aforementioned durability issues of the implanted biomaterial occurred in the midand long-term. Thus, the acute experimental setting is certainly the key limitation of this study. A chronic experimental model is mandatory before any further clinical use can be considered. The model should focus on the mid- and long-term histopathologic and immunologic alterations that appear to be the main cause of high failure rate and clearly address current doubts on the regenerative and antithrombogenic capacity of the 
ECM biomaterial. Consequently, much more work needs to be done to convince the congenital and adult cardiac surgery community about the efficacy and safety of the ECM tube graft technologies for valvular pathologies.

\section{References}

1. Mosala Nezhad Z, Poncelet A, de Kerchove L, Gianello P, Fervaille C, El Khoury G. Small intestinal submucosa extracellular matrix (CorMatrix ${ }^{\circledR}$ ) in cardiovascular surgery: a systematic review. Interact Cardiovasc Thorac Surg. 2016;22:839-50.

2. Gerdisch MW, Shea RJ, Barron MD. Clinical experience with CorMatrix extracellular matrix in the surgical treatment of mitral valve disease. $J$ Thorac Cardiovasc Surg. 2014;148:1370-8.

3. Gerdisch MW, Boyd WD, Harlan JL, Richardson JB Jr, Flack JE III, Palafox BA, et al. Early experience treating tricuspid valve endocarditis with a novel extracellular matrix cylinder reconstruction. J Thorac Cardiovasc Surg. 2014; 148:1042-50.

4. Zafar F, Hinton RB, Morre RA, Baker RS, Bryant R III, Narmoneva DA, et al. Physiological growth, remodeling potential, and preserved function of a novel bioprosthetic tricuspid valve: tubular bioprosthesis made of small intestinal submucosa-derived extracellular matrix. J Am Coll Cardiol. 2015;66:877-88.
5. Hibino N, McConnell P, Shinoka T, Malik M, Galantowicz M. Preliminary experience in the use of an extracellular matrix (CorMatrix) as a tube graft: word of caution. Semin Thorac Cardiovasc Surg. 2015;27:288-95.

6. Rao V. All that glitters is not gold-but it may be silver. J Thorac Cardiovasc Surg. 2017;154:e61-2

7. Padalino MA, Quarti A, Angeli E, Frigo AC, Vida VL, Pozzi M, et al. Early and mid-term clinical experience with extracellular matrix scaffold for congenital cardiac and vascular reconstructive surgery: a multicentric Italian study. Interact Cardiovasc Thorac Surg. 2015;21:40-9.

8. Zaidi AH, Nathan M, Emani S, Baird C, del Nido PJ, Gauvreau K, et al. Preliminary experience with porcine intestinal submucosa (CorMatrix) for valve reconstruction in congenital heart disease: histologic evaluation of explanted valves. J Thorac Cardiovasc Surg. 2014;148:2216-25.

9. Luk A, Rao V, Cusimano RJ, David TE, Butany JD. CorMatrix extracellular matrix used for valve repair in the adult: is there de novo valvular tissue seen? Ann Thor Surg. 2015;99:2205-20.

10. Kelley TM Jr, Kashem M, Wang H, McCarthy J, Carroll ND, Moser GW, et al. Anterior leaflet augmentation with CorMatrix porcine extracellular matrix in twenty-five patients: unexpected failures and histologic analysis. Ann Thor Surg. 2017;103:114-20.

11. Tjørnild MJ, Hanse LC, Skov SN, Poulsen KB, Sharghbin M, Benhassen LL, et al. Entire mitral reconstruction with porcine extracellular matrix in an acute porcine model. J Thorac Cardiovasc Surg. 2020;160:102-12.
See Article page 102.

\section{Commentary: Pig in a poke}

\author{
Edward Y. Sako, MD, PhD
}

In the accompanying article, Tjormild and colleagues ${ }^{1}$ describe a technique for mitral valve replacement using a modified tube graft. Sheets of a porcine 2-ply small intestinal submucosa extracellular matrix are fashioned into a tube with one end sewn to the mitral annulus and the other attached to the tips of the papillary muscles and cutouts done in such a way as create functional leaflets of the sides of the tube. This reconstruction was performed on 8 pigs, pre- and post-procedure physiologic and echocardiographic assessments were made, and the animals were then euthanized. The immediate results, including hemodynamics and videos of the echo, appear excellent. It is not an entirely novel concept but based in part on work done by this group in tricuspid valve replacement. ${ }^{2}$

From the Department of Cardiothoracic Surgery, University of Texas Health Science Center at San Antonio, Tex.

Disclosures: The author has a financial relationship with Medtronic, Inc.

Received for publication July 15, 2019; accepted for publication July 17, 2019; available ahead of print July $25,2019$.

Address for reprints: Edward Y. Sako, MD, PhD, Department of Cardiothoracic Surgery, University of Texas Health Science Center at San Antonio, Mail Code 7841,

7703 Floyd Curl Dr, San Antonio, TX 78229-3900 (E-mail: sako@uthscsa.edu).

J Thorac Cardiovasc Surg 2020;160:114-5

$0022-5223 / \$ 36.00$

Copyright (c) 2019 by The American Association for Thoracic Surgery

https://doi.org/10.1016/j.jtcvs.2019.07.030

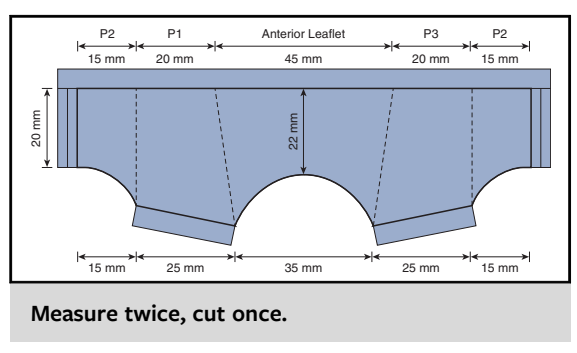

CENTRAL MESSAGE

An intriguing alternative to mitral valve replacement will depend largely on the ease of implant and durability of the extracellular matrix.

The keys to the success of the technique will depend on the standardization of the methods to achieve the correct measurements to accommodate the variations in anatomy and the ultimate durability of the material. The measurements given appear rather proscriptive but given the design would likely have to be customized to the individual anatomy. Thus, the first question many surgeons will ask is how easy and replicable is the implant technique? Given 